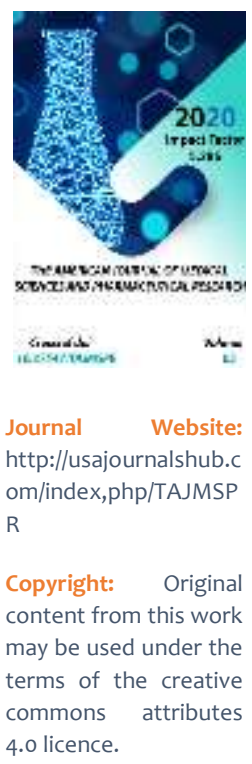

\title{
Assessment Of Some Functional Indicators Of The Oral Cavity Working In Tobacco Production
}

\author{
Nazarova Nodira Sharipovna \\ Candidate Of Medical Sciences, Associate Professor Of The Department Of Dentistry, Faculty \\ Of Postgraduate Education, Uzbekistan
}

Sitora Baizakova

Assistant Of The Department Of Pediatric Dentistry, Uzbekistan

Sevinch Ismailova

Second Year Master's Student, Samarkand State Medical Institute, Uzbekistan

\section{ABSTRACT}

To date, it has been established that $70 \%$ of people involved in tobacco growing have various diseases $[4,6$,$] . Comparison of morbidity rates with temporary disability of workers employed in tobacco$ growing and the control group shows that tobacco growers get sick more often than others. The number of diseases they have is $37 \%$, and the number of days of disability is $30 \%$ higher than in other types of agricultural work $[8,4,1]$. Diseases of the respiratory and gastrointestinal tract, infectious and allergic diseases, nervous and cardiovascular systems, skin and subcutaneous tissue occupy the leading place in the structure of tobacco growers' morbidity.

However, there is no information on the impact of unfavorable factors of the tobacco-growing industry on the organs and tissues of the oral cavity of workers and the corresponding therapeutic and prophylactic measures, with the exception of individual works [7,2] in the form of an article, where long-term exposure to tobacco extract under experimental conditions, combined with a single dose and a population herpes simplex virus, cause clinical and morphological changes resembling leukoplakia.

\section{KEYWORDS}

Harmful production factors, tobacco growing, oral mucosa, hygiene index. 


\section{INTRODUCTION}

It is known that the pathology of the oral cavity occupies a large proportion of workers in various chemical industries [1.5], but the available literature provides little information on the study of professional pathology of the dental system when the body is exposed to adverse production factors in tobacco production (nicotine, ammonia, asparagine, amines, amino acids, essential oils, resins and pesticides) $[4,8]$.

Meanwhile, there is evidence in the literature that functional disorders of the oral organs are early preclinical signs of occupational exposure to toxic substances on the body $[2,3]$.

The purpose of this study was to study the state of certain clinical and functional indicators of the oral cavity in tobacco workers $[6,9]$.

\section{MATERIAL AND METHODS}

We studied the state of some clinical and functional indicators of the oral cavity (oral hygiene index, acid resistance of enamel, electrical conductivity of hard tooth tissues, Schiller-Pisarev and kulazhenko samples) in 84 workers in the Urgut tobacco growing district of the Samarkand viloyat (main group). For comparison, a similar study was conducted in 82 workers and the population in the Samarkand vegetable growing district of the same viloyat, who had similar microclimatic, social and living conditions, but differed only in the absence of production and harmful factors (control group).

To obtain more comparable data and exclude the influence of gender, age, and work experience on the studied indicators, studies were conducted only in men aged 21-40 years with up to 5 years of work experience in both study areas. For comparison, functional indicators at the physiological norm are also given $[5,7]$.

To assess the acid resistance of tooth enamel, the method of T. A. Redinova et al. (1982) was used, the electrical conductivity of hard tooth tissues was studied using the method of G. G. Ivanova (1984), the state of periodontal tissues was evaluated using the Schiller-Pisarev test, the oral hygiene index was calculated by L. V. Fedorova (1982), and the capillary resistance of periodontal tissues was determined using the method of V. I. kulazhenko (1960).

The obtained data were processed using the Microsoft Excel program, the reliability of differences was determined by the student's criterion.

\section{RESULTS AND DISCUSSION}

The analysis of the results of the conducted studies (table) showed that the level of oral hygiene was equally $(P>0.05)$ low in both groups of the examined patients.

The susceptibility of tooth enamel to the acid buffer from working in tobacco farming was 19.6\% $(P<0.001)$ lower than the control group, and the electrical conductivity of hard tissues of teeth, on the contrary, above $1.4 \mu \mathrm{\mu a}$ $(\mathrm{P}<0.001)$ that indicate, in our view, on emerging risk factor for dental caries and is the earliest sign of this disease among growers.

When analyzing the data from the SchillerPisarev and kulazhenko samples, it was found that chronic inflammatory processes in the gums are $30.7 \%(\mathrm{P}<0.001)$ more common in tobacco workers than in the control group, and capillary resistance in periodontal tissues 
decreases by $18 \mathrm{~s}(\mathrm{P}<0.001)$. These data confirm the results of our clinical studies that chronic gingivitis and periodontitis are more common among tobacco workers than in those working in the vegetable growing control area.

Table

Clinical and functional indicators of the oral cavity in tobacco workers and in the control $\operatorname{group}(\mathbf{M} \pm \mathbf{m})$

\begin{tabular}{|c|c|c|c|c|}
\hline \multirow[t]{2}{*}{ Studied indicators } & \multirow{2}{*}{$\begin{array}{c}\text { Physiolo } \\
\text { gical } \\
\text { norm }\end{array}$} & \multicolumn{2}{|c|}{ Group of workers } & \multirow{2}{*}{$\begin{array}{l}\text { Reliabi } \\
\text { Lity, P }\end{array}$} \\
\hline & & basic & control & \\
\hline Hygiene index, score & $0-1$ & $5.9 \pm 0.8$ & $5.7 \pm 0,7$ & $>0,05$ \\
\hline Acid resistance of enamel, \% & 40 & $64,8 \pm 2,7$ & $45,2 \pm 1,8$ & $<0,001$ \\
\hline $\begin{array}{c}\text { Electrical conductivity of hard tissues of } \\
\text { teeth, mkA }\end{array}$ & 0 & $3,2 \pm 0,4$ & $1,8 \pm 0,07$ & $<0,01$ \\
\hline Schiller-Pisarev Test, \% & 0 & $75,5 \pm 1,7$ & $44,8 \pm 1,3$ & $<0,001$ \\
\hline Kulazhenko sample, s. & $50-60$ & $28,0 \pm 1,4$ & $46,0 \pm 1,5$ & $<0,001$ \\
\hline
\end{tabular}

When analyzing the incidence of dental caries in the same age and experience subgroups of the compared groups of subjects, it was found that the prevalence $(87.3 \pm 2.9 \%)$ and intensity (CPI index $=7.3 \pm 0.6)$ of dental caries lesions were significantly higher $(P<0.01)$ than in the control group of subjects $(73.3 \pm 2.5 \%$ and $5.5 \pm 0.5 \%$, respectively). It is characteristic that in most cases, the initial caries of tobacco workers was asymptomatic, and the transition from the superficial to the deep form occurred without any special subjective feelings and in a short time. It was also revealed that in some of the examined patients, the localization of carious lesions was atypical due to an increase in the specific weight of cavities in the contact and cervical areas of the teeth.
Analysis of the frequency of dental caries in the main and control groups of the examined in the age aspect revealed that the difference in the prevalence of dental caries in the compared groups of the examined was significant $(P<0.05-0.001)$ in all age groups.

As the length of service in tobacco production increased, the average prevalence of caries and the CPI index significantly increased. If you consider that in tobacco the majority of working person who crosses the threshold of the third decade, in an age when under normal conditions should occur relative stabilization of the caries process, among the growers, on the contrary, an increase in the number of decayed teeth. However, it should be noted that the indicators of dental caries in tobacco growers 
with an experience of 5 to 9 years did not differ significantly from those in the group with an experience of up to 5 years, but significantly increased with an experience of more than 10 years. In the following study groups - 15-19 years and 20 years or more - the increase in caries indicators was also not observed.

It is characteristic that when examining the oral cavity of tobacco growers in most cases, a small hole and a significant amount of lowpigmented softened dentin in the cavities were found in carious teeth. This circumstance indicates the severity of the carious process. This was also evidenced by the high proportion of complicated caries among tobacco workers (52.3? $2.9 \%)$ than its uncomplicated forms (36.1?2.0\%).

Thus, based on the results of these studies, we can say that in the development of dental caries in tobacco growers, an unfavorable production environment in tobacco production has a certain significance. This is evidenced by the comparative assessment of data obtained from growers with control group patients, the increase of caries with age and direct correlation between the intensity of caries and the duration of work in tobacco farming.

\section{CONCLUSIONS}

Thus, after analyzing our own and literature data, we can say that in the tobacco industry, workers show a decrease in the acid resistance of enamel, an increase in the electrical conductivity of hard tooth tissues and a decrease in the resistance of gum capillaries, which, in all probability, precede the development of dental caries and periodontal diseases among tobacco growers. Therefore, these violations can serve as integral indicators of the negative impact of tobacco production factors on the health and condition of the oral cavity of workers.

\section{REFERENCES}

1. Garus Ya. N., Olesova V. N., Uiba V. V., Sorokoumov G. L. Comparative indicators of the intensity of dental caries in nuclear power plant personnel depending on the dose of ionizing exposure //Dentistry.2006. - No. 3.-P. 18-19.

2. Obraztsov Yu. L. Environmental aspects of dental pathology //Dentistry.-1997. - no. 5.P. 75-79.

3. Pekker R. Ya. Occupational lesions of oral tissues.-M., - 1987. -25 p.

4. Suleymanova G. G., Petrovich Yu. a., Ratner K. V. influence of tobacco, herpes simplex virus and antioxidants on free radical oxidation in the oral mucosa //Dentistry.1998. - No. 4.-P. 12 -

5. Tupshevits O. N., Fedorova N. G. State of dental health in metallurgical production workers //Russian dental journal.-2007. no. 2.-P. 28-31.

6. Nazarova N. Sh., Zhumatova N. Zh., Kasimov M. M. The state of local immunological reactivity of the oral cavity in workers in the tobacco industry // Journal of theoretical and clinical medicine, Tashkent - 2014. - no. 4. - P. 17-19.(14.00.00; no. 3).

7. Nazarova N. Sh., Zhumatov U. Zh. Characteristics of functional conditions of taste analyses of tobacco cultivation employees. European Science. Review. Scientific jurnal. Austria, Vienna. 2015. - № 7-8. - P. 41-43. (14.00.00; №19).

8. Nazarova N. Sh., Zhumatov U. J. Efficacy of physiotherapy with periodontitis have growers // Journal of Problems of biology and medicine, Samarkand - 2014. - № 4 (80). - P. 79 . 
9. Tooth loss, prosthetic status and treatment needs among industrial workers in Belgaum, Karnataka, India / V. V. Patil, K. Shigli, M. Hebbal, N. Agrawal // J. Oral Sci. 2012. - Vol. 54, No. 4. - P. 285-92. 